\title{
DIAGNÓSTICO FÍSICO-AMBIENTAL EM PLANOS DIRETORES: um relato de experiência
}

\author{
Prof $^{a}$. Dr ${ }^{\mathrm{a}}$. Cenira Maria Lupinacci da Cunha \\ Programa de Pós-Graduação em Geografia, UNESP, Campus de Rio Claro \\ Av. 24A, n.1515 - CEP 13506900 Rio Claro (SP) - Brasil \\ Tel: (55 19) 3526.9355 - cenira@rc.unesp.br \\ Prof. Dr. Rodrigo Braga Moruzzi \\ rmoruzzi@rc.unesp.br \\ Prof. Dr. Roberto Braga \\ rbraga@rc.unesp.br
}

\section{RESUMO}

O Plano diretor é um instrumento de caráter tanto técnico como político, devendo sua elaboração ter obrigatoriamente caráter participativo. Em seu processo de elaboração, tanto no nível técnico, como no comunitário, devem ser abordadas questões de diversas naturezas, relativas ao desenvolvimento urbano, inclusive as que afetam o saneamento e o meio ambiente. Neste contexto, o objetivo deste artigo é apresentar as técnicas utilizadas e discutir os resultados obtidos no diagnóstico físico ambiental realizado para compor o Plano Diretor do município de Rio Claro e de Iracemápolis, estado de São Paulo. A partir das experiências relatadas foi possível identificar procedimentos técnicos adequados para tal trabalho, assim como verificar problemas que podem surgir na elaboração dos referidos diagnósticos.

Palavras-Chave: plano diretor, diagnóstico, dados físico-ambientais.

\begin{abstract}
The Urban Plans are technical and politician tools and their elaboration must have citizen involvement. Thus, several aspects must be taken into account while preparing it including both technical and communitarian urban development besides environmental and sanitation features. The paper aim is to present the applied techniques and to discuss the results obtained from physical and environmental diagnostic made to prepare Rio Claro and Iracemápolis Urban Plans. From the presented experiences it was possible to identify adequate technical proceedings as well as to verify general problems that can emerge during Urban Plan diagnostic phase.
\end{abstract}

Key words: Urban Plan, diagnostic, physical and environmental data.

\section{RESUMEN}

El plan director es un instrumento con carácter técnico y político, teniendo su elaboración, carácter participativo obligatorio. En su proceso de elaboración, tanto en el aspecto técnico como en el politico, deben estar presentes cuestiones concernientes al desarrollo urbano y también las que afectan el saneamiento y el ambiente. En este contexto, el objetivo de este artículo es presentar las técnicas usadas y discutir los resultados conseguidos en la diagnosis física y ambiental llevada a cabo para la elaboración del plan directoe de las ciudades de Río Claro y de Iracemápolis, estado de São Paulo. De las experiencias fue posible identificar los procedimientos técnicos más adecuados para tal trabajo, así como verificar los problemas que pueden aparecer en la elaboración de la diagnosis.

Palabras-clave: plan director, diagnosis, datos fisico ambientales.

\section{INTRODUÇÃO}

O Plano Diretor é o instrumento básico da política urbana executada pelo poder público municipal. Consiste num conjunto de normas que regem o desenvolvimento, o uso, a expansão e o parcelamento do solo urbano, bem como a implantação da infra-estrutura e equipamentos urbanos. Foi tornado obrigatório, por força da Constituição Federal, para todas as cidades com mais de 20 mil habitantes e sua elaboração é regida pela lei federal 10.257 de 10 de julho de 2001, também conhecida como Estatuto da Cidade.

O Plano diretor é um instrumento de caráter tanto técnico como político, devendo sua elaboração ter obrigatoriamente caráter participativo. O Ministério das Cidades recomenda que seu processo de elaboração seja precedido de uma etapa de diagnóstico denominada "Leitura da Cidade", que se daria em dois níveis: o "Técnico" e o "Comunitário" (BRASIL, 2004). 
A leitura técnica deve ser desenvolvida pelo corpo técnico da prefeitura ou com ajuda de consultoria especializada e deve diagnosticar os problemas socioeconômicos, urbanísticos, ambientais e administrativos da cidade.

A leitura comunitária é realizada através de dinâmicas participativas com a comunidade e visa identificar problemas e demandas e propor medidas e prioridades para o Plano Diretor.

Em seu processo de elaboração, tanto no nível técnico, como no comunitário, devem ser abordadas questões de diversas naturezas, relativas ao desenvolvimento urbano, inclusive as que afetam o saneamento e o meio ambiente, pois em sua perspectiva está o desenvolvimento sustentável, como assim determina o próprio Estatuto da Cidade em seu artigo segundo. Conforme Xavier (1992, p. 27):

O plano diretor contempla a vertente ambiental em diferentes escalas de abordagem, que variam desde o nível macro, espelhado nas diretrizes para o desenvolvimento urbano e para a definição da política de meio ambiente, até o nível pontual, que se reflete nos parâmetros para o uso e ocupação do solo estabelecidos pela legislação urbanística, bem como na fixação de parâmetros de controle ambiental, através de leis específicas.

Portanto, na elaboração dos diagnósticos, ou leituras da cidade, há de se considerar a avaliação das condições ambientais das cidades, tanto no que se refere ao meio natural, como antrópico.

Neste contexto, o objetivo deste artigo é apresentar as técnicas utilizadas e discutir os resultados obtidos no diagnóstico físico ambiental realizado para compor os Planos Diretores dos municípios de Rio Claro e de Iracemápolis (Figura 1). Ambos os municípios estão situados na Região Administrativa de Campinas, no Estado de São Paulo, numa área com fortes características industriais e agroindustriais.

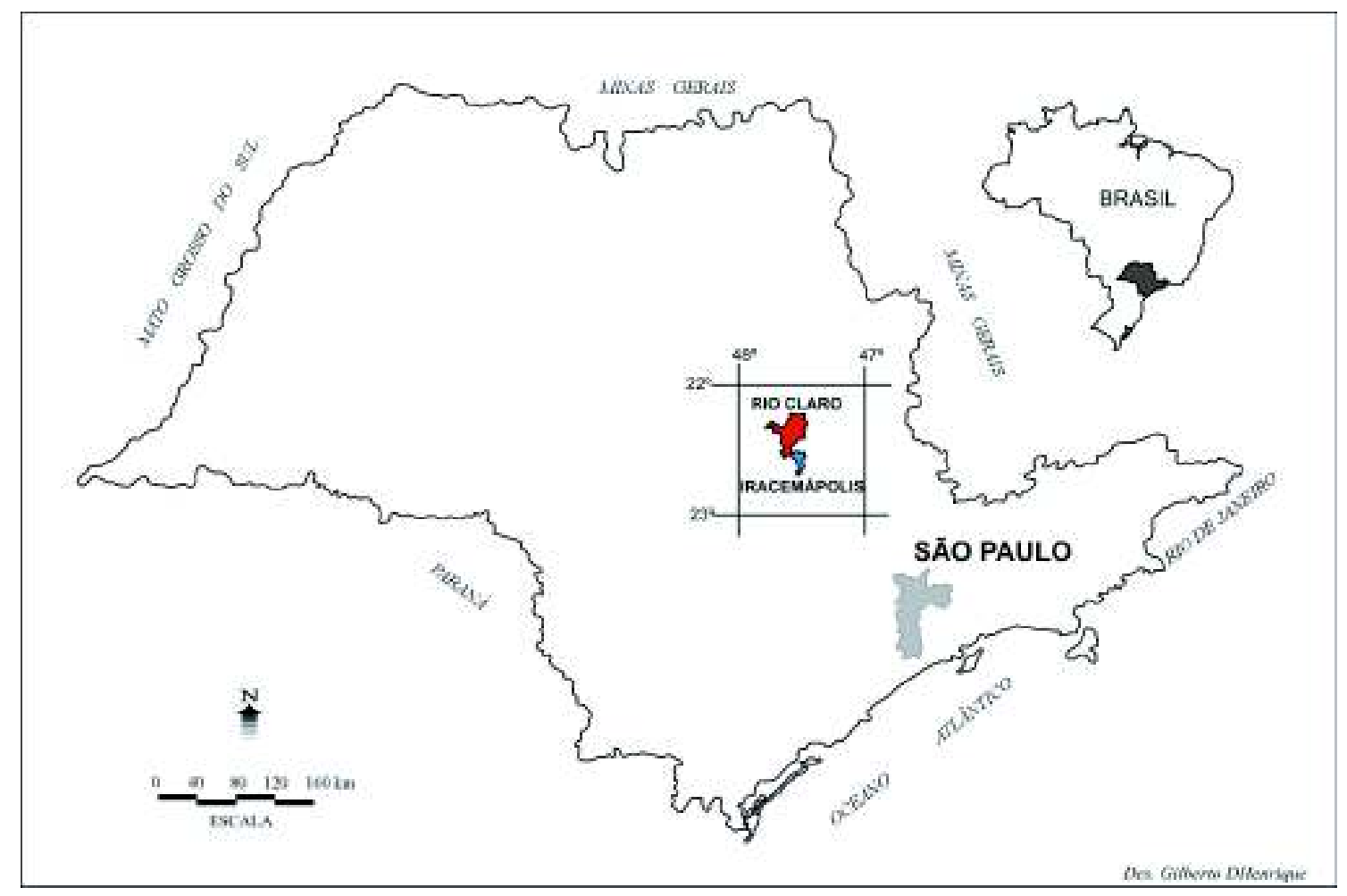

Figura 1 - Localização dos municípios de Rio Claro e Iracemápolis no estado de São Paulo.

O município de Rio Claro caracteriza-se por ter como sede uma cidade de porte médio (cerca de 180 mil habitantes), enquanto o município de Iracemápolis compreende uma cidade de pequeno porte (cerca de 17 mil habitantes). Ambos possuem altas taxas de urbanização $(97,87 \%$ e 96,56\%, respectivamente) e taxas de crescimento demográfico acima da média estadual $(1,87 \%$ e $2,17 \%$ ao ano, respectivamente). A experiência adquirida na elaboração desses planos diretores permitiu avaliar a importância e as dificuldades de se realizar o diagnóstico físico ambiental como parte 
integrante deste instrumento. Entende-se por dados físico ambientais um conjunto de informações sobre os aspectos naturais dos municípios, os quais são compostos por geologia, solos, relevo, clima e hidrografia, e informações sobre os impactos provocados pelo uso e ocupação da terra em tais aspectos naturais. Atualmente é impossível avaliar os aspectos naturais sem considerar as alterações antrópicas, muitas já consolidadas, sobre tais elementos. Assim, a seguir apresentam-se os procedimentos técnicos utilizados para realizar o levantamento dos dados físicos ambientais desses municípios.

\section{PROCEDIMENTOS TÉCNICOS}

Apesar da ênfase dos planos diretores no caráter urbano do município (daí a lei geral intitularse Estatuto da Cidade), o diagnóstico ambiental não deve se restringir ás áreas urbanizadas. Deve abranger todo o município, em especial as áreas peri-urbanas e de expansão urbana, assim como aquelas de interesse especial para o desenvolvimento urbano, como as áreas de mananciais. Assim, o levantamento dos dados físico ambientais deve obrigatoriamente contemplar tanto áreas urbanas quanto rurais. Dessa forma, os procedimentos técnicos e as etapas efetuadas para o levantamento de tais dados nos planos diretores de Rio Claro e Iracemápolis foram:

1. Pesquisa cartográfica sobre a área de estudo: tal pesquisa buscou documentos cartográficos básicos, como cartas topográficas de diversas escalas, assim como documentos cartográficos temáticos, principalmente, aqueles referentes à geologia, solos e hidrografia. As cartas topográficas de diferentes escalas visavam avaliar tanto o espaço territorial completo do município, como, com maior detalhe, a área urbana e seu entorno. Essa análise em escala de detalhe fazse necessária para avaliar o declive do terreno e a distribuição da rede hidrográfica visto que tais dados são imprescindíveis para a aplicação da legislação ambiental referente à expansão urbana e identificação de áreas de preservação permanente.

2. Pesquisa bibliográfica sobre o contexto regional: esta pesquisa visou identificar o contexto regional onde se insere o espaço municipal a ser analisado. A ênfase maior foi dada à identificação da bacia hidrográfica e a unidade de gerenciamento dos recursos hídricos sobre as quais se assentam os espaços municipais analisados. Esta informação é estratégica para a questão de disponibilidade e gerenciamento da água nos municípios.

3. Elaboração dos documentos cartográficos: com base nos documentos cartográficos temáticos obtidos na fase 1 , foram organizados mapas referentes à geologia, solos e uso da terra dos municípios. Através das cartas topográficas levantadas foi possível construir mapas de declividade e hipsométricos dos municípios e, em escala de detalhe (1:10.000), da área urbana e seu entorno próximo. Este procedimento específico para a área urbana faz-se necessário, pois a declividade é parâmetro geomorfológico definidor das possibilidades de uso e expansão urbana de acordo com várias normatizações constantes nos instrumentos da atual legislação ambiental. A maior dificuldade nesta fase referiu-se à incompatibilidade de escalas entre os dados existentes na bibliografia e aquelas adequadas à análise necessária em um plano diretor. Assim, muitos dados tiveram que ser reambulados em campo.

4. Trabalhos de campo: os trabalhos de campo visaram tanto reambular os dados físicos mapeados, como verificar problemas ambientais existentes. As informações dos órgãos municipais foram imprescindíveis nesta fase para direcionar tais trabalhos. Além dessas questões, o entorno urbano foi percorrido e analisado em detalhe visando levantar informações que apontassem as possibilidades e restrições de tais áreas à expansão urbana. Considera-se que este procedimento é essencial para a elaboração de um plano diretor o qual, efetivamente, constitua-se em instrumento de gerenciamento urbano. 
5. Análise dos dados: a análise dos dados foi elaborada em duas fases distintas as quais estão refletidas na organização dos textos sobre os aspectos físico ambientais dos municípios. Assim, apresenta-se inicialmente a caracterização física ambiental dos municípios e de suas áreas urbanas. A seguir, realiza-se o diagnóstico físico ambiental o qual se baseia na interpretação qualitativa das suscetibilidades potenciais das características físicas ambientais existentes e nos dados levantados em campo sobre os problemas ambientais já efetivos.

6. A redação final: essa foi uma etapa estratégica na realização do diagnóstico físico ambiental. A redação deve ser feita de tal forma que possibilite a discussão pública dos dados levantados, bem como o entendimento por técnicos de outras áreas, já que o Plano Diretor envolve uma equipe multidisciplinar. Dessa forma, a linguagem técnica teve que ser amplamente simplificada.

Ainda sobre os procedimentos técnicos, no caso da área urbana de Rio Claro, o diagnóstico físico ambiental foi elaborado de acordo a divisão da área urbana em unidades regionais. Tais unidades foram definidas por Carvalho e Braga (2005) tanto em função das bacias hidrográficas, e, portanto, das características físicas da área, como em função de características sócio-econômicas, do uso do solo e dos perfis econômico e demográfico da população. A utilização destas unidades espaciais foi procedimento necessário para o gerenciamento dos dados, em grande quantidade devido a própria dimensão do espaço urbano, bem como para facilitar a organização posterior do zoneamento urbano.

\section{RESULTADOS E DISCUSSÕES}

Os procedimentos técnicos relatados geraram um universo de dados bastante amplo, os quais precisavam ser sistematizados de maneira clara e concisa a fim de auxiliar o gerenciamento do espaço municipal por técnicos da prefeitura, assim como serem compreendidos por públicos variados nas audiências públicas necessárias para a aprovação dos referidos planos diretores.

Para satisfazer tantos objetivos diferentes, optou-se por organizar tais dados em duas seções. Na primeira, denominada de caracterização físico ambiental, os dados foram apresentados de maneira mais técnica, descrevendo-os com termos próprios de cada área de conhecimento. Assim, os dados geológicos, pedológicos, de relevo, climáticos, hidrográficos e de uso da terra, e os mapas, que espacializavam tais dados, foram compilados de forma tradicional. Acredita-se que dessa maneira os técnicos das prefeituras possam se valer de um conjunto de informações úteis a tomada de decisões sobre o gerenciamento do espaço municipal.

Na segunda seção buscou-se interpretar os dados técnicos referentes às características físico ambientais da área a fim de apresentar ao público não técnico o significado das informações anteriormente descritas com linguagem científica. Como exemplo apresenta-se um trecho da redação do diagnóstico do plano diretor de Rio Claro:

Quanto aos aspectos geológicos, o município de Rio Claro está inserido na borda nordeste da Bacia Sedimentar do Paraná e apresenta, portanto, litologias cuja composição e, principalmente, formas de contato, representam fragilidades erosivas significativas. Assim, o contato entre a Formação Corumbataí, que aflora predominantemente nos vales, e a Formação Rio Claro, que capeia principalmente os setores de interflúvios entre o Ribeirão Claro-Corumbataí, Corumbataí-rio da Cabeça, se faz por discordância erosiva. Processos erosivos instalados e cabeceiras de drenagens ocorrem com freqüência neste contato discordante entre tais formações (PLANO DIRETOR DO MUNICÍPIO DE RIO CLARO, 2006).

No texto acima transcrito busca-se enfatizar o significado das informações apresentadas anteriormente. Assim, em vez de discutir as características das formações geológicas, explora-se o significado destas que, neste caso, refere-se a sua potencial fragilidade erosiva. 
Para o plano diretor de Iracemápolis, a discussão do significado de cada característica física foi sistematizada na forma da tabela a seguir apresentada:

Tabela 1: Principais características dos elementos físicos que interferem nas condições físico-ambientais de Iracemápolis (SP).

\begin{tabular}{|l|l|}
\hline \multicolumn{1}{|c|}{ Elemento Físico. } & \multicolumn{1}{c|}{ Característica Relevante. } \\
\hline Clima. & $\begin{array}{l}\text { Clima Tropical - Verão Chuvoso e Inverno Seco, gerando irregularidade na presença das } \\
\text { águas ao longo do ano. }\end{array}$ \\
\hline Substrato Litológico. & Discordâncias erosivas entre as formações litológicas. \\
\hline Variáveis do Solo. & Presença de Argissolos que apresentam alta suscetibilidade aos processos erosivos. \\
\hline Relevo. & $\begin{array}{l}\text { Relevo suavizado da Depressão Periférica Paulista que pode implicar em dificuldades para } \\
\text { o escoamento das águas pluviais, principalmente nos setores urbanos. }\end{array}$ \\
\hline
\end{tabular}

Fonte: Plano Diretor de Iracemápolis (SP).

Mesmo quando se tratava de questões referentes à ocupação humana, buscou-se apresentar a linha de raciocínio das relações estabelecidas de forma detalhada, como por exemplo, no trecho a seguir:

Os componentes fisiográficos do município de Rio Claro, vêm sofrendo interferências antrópicas refletindo em alterações no meio ambiente decorrentes do uso e ocupação da terra. De forma geral, esta ocupação relaciona-se à tendência da agricultura do interior do estado de São Paulo, principalmente com o desenvolvimento do setor sucro-álcooleiro regional, que causa o avanço da monocultura canavieira em detrimento de áreas de pastagem, áreas de preservação permanente e matas ciliares. (PLANO DIRETOR DO MUNICÍPIO DE RIO CLARO, 2006).

No plano diretor do município de Rio Claro, a caracterização, assim como o diagnóstico, foram realizados e apresentados em duas seções: uma para o município como um todo e outra detalhada para a área urbana. Este procedimento também visou facilitar a leitura do universo de dados obtidos. Assim, verificou-se que quanto mais extensa a área urbana, mais dados são necessários para avaliar sua possível expansão, demandando organização destes de forma mais sistemática a fim de garantir a eficiência da análise.

Para que esta eficiência se processe e a comunicação do diagnóstico seja efetiva, procurouse sistematizar através de tabelas os dados referentes aos impactos ambientais identificados em trabalhos de campo (Tabela 2).

Para o plano diretor de Rio Claro buscou-se identificar separadamente, como apresentado na tabela anterior, os problemas referentes à área urbana. $\mathrm{O}$ diagnóstico rural foi menos detalhado, apresentando somente possíveis fragilidades derivadas da análise das características físicas e de alguns problemas identificados em campo.

A experiência com o plano diretor de Rio Claro demonstrou que os termos identificadores da tabela, "Categorias" e "Ocorrências", podiam gerar dúvidas aos leitores não técnicos. Assim, para o plano diretor de Iracemápolis tais termos foram subtraídos, buscando simplificar a linguagem utilizada (Tabela 3). 
Tabela 2: Principais Impactos Ambientais na área urbana e periferia de Rio Claro.

\begin{tabular}{|l|l|}
\hline \multicolumn{1}{|c|}{ CATEGORIAS } & \multicolumn{1}{c|}{ OCORRẼNCIAS } \\
\hline Processos Erosivos. & $\begin{array}{l}\text { Erosão linear acelerada (sulcos erosivos, ravinamentos e } \\
\text { voçorocas) e processos de retomada erosiva dos cursos fluviais. }\end{array}$ \\
\hline Assoreamento dos Cursos Fluviais. & $\begin{array}{l}\text { Depósitos, em fundo de vale, vinculados a materiais cuja } \\
\text { origem deve-se a processos erosivos lineares, a exploração } \\
\text { mineral, a resíduos sólidos e entulhos. }\end{array}$ \\
\hline Avanço da Urbanização nos Vales Fluviais. & $\begin{array}{l}\text { Avanço da urbanização em áreas de fundo de vale que se } \\
\text { constituem em APPs (Áreas de Preservação Permanente). }\end{array}$ \\
\hline Enchentes e Inundações. & $\begin{array}{l}\text { Planícies de inundação ocupadas por ruas, avenidas e } \\
\text { construções que sofrem alagamento. }\end{array}$ \\
\hline Áreas Deprimidas Aterradas (Lagos e Lagoas). & Dificuldade para o escoamento das águas pluviais. \\
\hline Áreas de Exploração Mineral, Depósitos de Lixo e Entulho. & $\begin{array}{l}\text { Cavas ativas ou desativadas com processos erosivos ativos, } \\
\text { junto a depósito de resíduos. }\end{array}$ \\
\hline
\end{tabular}

Fonte: Plano Diretor de Rio Claro (SP).

No caso de Iracemápolis, o diagnóstico e a tabela de compilação já apresentada englobam problemas tanto urbanos como rurais. Isso foi pertinente devido à inter-relação nítida entre tais problemas o que exigiu que as relações de causa e efeito fossem consideradas dentro de uma totalidade em termos espaciais.

Tabela 3: Principais Impactos Ambientais em Iracemápolis

\begin{tabular}{|l|l|}
\hline \multicolumn{1}{|c|}{ Impactos Ambientais } & \multicolumn{1}{c|}{ Situação } \\
\hline Processos Erosivos Instalados. & $\begin{array}{l}\text { Associados a retirada da cobertură vegetal, a ocupação humana e } \\
\text { as retomadas erosivas de das margens dos cursos fluviais devido a } \\
\text { alterações antrópicas. }\end{array}$ \\
\hline Assoreamento dos Cursos Fluviais. & $\begin{array}{l}\text { Sedimentos oriundos dos processos erosivos instalados, além de } \\
\text { entulho e lixo, que são carreados para os leitos fluviais. }\end{array}$ \\
\hline Represamento dos Cursos Fluviais. & $\begin{array}{l}\text { Encontra-se por todo município, principalmente em áreas de } \\
\text { nascentes. Estes represamentos interferem diretamente na } \\
\text { dinâmica do escoamento fluvial. }\end{array}$ \\
\hline Aterramento de antigas Áreas de Terraços. & $\begin{array}{l}\text { Canalização dos cursos fluviais encontrados no setor urbano, } \\
\text { interferindo na dinâmica de escoamento. }\end{array}$ \\
\hline Ocupação Urbana e Rural em Áreas Deprimidas de Topo. & $\begin{array}{l}\text { Aterros para a ocupação urbana em áreas de antigos terraços } \\
\text { aluvionares. }\end{array}$ \\
\hline Retirada da Mata Ciliar. & áreas de lençol freático aflorante. \\
\hline
\end{tabular}

Fonte: Plano Diretor de Iracemápolis (SP).

Todos os impactos inicialmente compilados no texto do diagnóstico através das tabelas foram discutidos e ilustrados através de fotografias. No caso de Rio Claro, procurou-se ainda sistematizar a localização dos problemas ambientais e apresentar de forma sintética tais dados através da figura a seguir. 


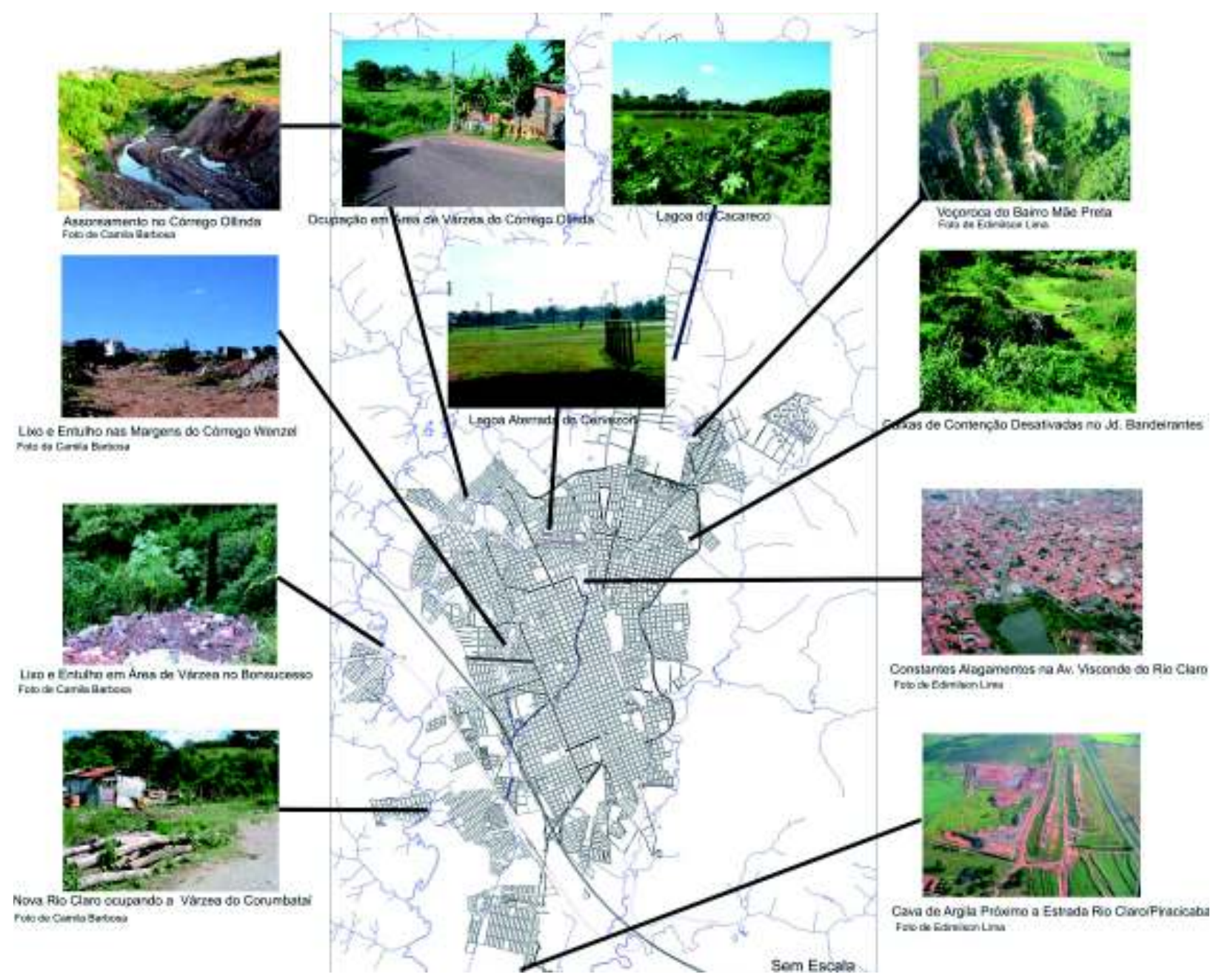

Figura 2 - Localização dos problemas ambientais da área urbana e da periferia de Rio Claro (SP).

A figura 2, utilizada em audiência pública, visa também facilitar o processo de comunicação dos dados do diagnóstico, recorrendo à associação dos recursos da fotografia e mapa. Através desta é possível ao público visualizar os fatos narrados no diagnóstico e reconhecer os problemas apontados.

\section{CONSIDERAÇÕES FINAIS}

O levantamento, análise e compilação dos dados físico-ambientais constituem etapa importante na elaboração de planos diretores visto que este tipo de informação auxilia a leitura das possibilidades e restrições impostas pelo meio para o desenvolvimento municipal. As experiências aqui apresentadas permitem algumas avaliações importantes, a saber:

1. O maior desafio para os técnicos que elaboram os planos diretores é desprender-se da linguagem técnico-científica normalmente já arraigada na prática cotidiana destes profissionais. Assim, para facilitar a comunicação, a construção de figuras e o uso de imagens, principalmente fotográficas, são de grande valia.

2. Para a obtenção das informações físico ambientais, o levantamento do material cartográfico, mesmo que em escala menos adequada, é imprescindível. A partir dos dados existentes é possível, através de reambulação em campo, construir documentos cartográficos temáticos importantes para a avaliação das fragilidades ambientais do território municipal. 
3. Faz-se necessário que as possíveis áreas de expansão urbana, assim como toda área periférica das cidades, sejam investigadas "in loco". Esse procedimento é importante já que é impossível avaliar as fragilidades desses terrenos somente por informações cartográficas ou das secretarias municipais. Muitas questões são desconhecidas das secretarias e são difíceis de serem registradas cartograficamente.

4. Quanto maior a área urbana, maior a dificuldade para o gerenciamento dos dados físico ambientais e para o levantamento dos problemas efetivos. Assim, a divisão da área urbana em unidades regionais, como no caso de Rio Claro, auxilia este processo.

5. O levantamento e análise dos dados físico ambientais da área rural é procedimento importante já que, como no caso de Iracemápolis, muitos problemas urbanos mantêm estreita relação com os espaços rurais.

Dessa forma, apesar das dificuldades apontadas, considera-se que os procedimentos técnicos apresentados possibilitaram, a elaboração de diagnósticos físico ambientais de grande valor para o zoneamento urbano e para o reconhecimento das fragilidades ambientais dos espaços rurais.

\section{REFERÊNCIA BIBLIOGRÁFICA}

BRASIL. Plano Diretor Participativo - Guia para a Elaboração pelos Municípios e Cidadãos. Brasília: Ministério das Cidades.2004.

CARVALHO, P. F. de, BRAGA, R. Zoneamento ambiental urbano por micro-bacias hidrográficas: estudo de viabilidade em cidade média no Estado de São Paulo -BR In: I Congresso Luso Brasileiro para o Planejamento Urbano, Regional Integrado e Sustentável, 2005, São Carlos - SP. Anais. São Carlos-SP: EESC-USP, 2005. v.1. p.1 - 12.

IRACEMÁPOLIS (Cidade). Plano Diretor do Município de Iracemápolis. Iracemápolis: Prefeitura Municipal, 2006.

RIO CLARO (Cidade). Plano Diretor do Município de Rio Claro. Rio Claro: Prefeitura Municipal, 2006. XAVIER, H. N.. Município, desenvolvimento urbano e meio ambiente. In. LOYOLA, C. de B. \& XAVIER, H. N. Município, desenvolvimento e meio ambiente. Rio de Janeiro: IBAM/CDM, 1992.

Trabalho enviado em setembro de 2009

Trabalho aceito em dezembro de 2009 